\title{
Dinâmicas institucionais e interações sociais: os efeitos não planejados da modernização da agricultura no Brasil e na França
}

\author{
Institutional dynamics and social interactions: the unplanned effects of the \\ modernization of agriculture in Brazil and France
}

\section{Dynamiques institutionnelles et les interactions sociales: les effets imprévus de modernisation de l'agriculture au Brésil et en France}

\author{
Dinámicas institucionales y las interacciones sociales: los efectos no previstos de \\ modernización de la agricultura en Brasil y en Francia \\ Ramonildes Alves Gomes* \\ (rnildes@hotmail.com) \\ Roberto de Sousa Miranda* \\ (robertosmiranda@.yahoo.com.br) \\ Recebido em 07/08/2015, revisado e aprovado em 23/09/2015; aceito em 20/11/2015 \\ DOI: http://dx.doi.org/10.20435/1518-70122016113
}

\begin{abstract}
Resumo: O objetivo do artigo é analisar as dinâmicas que influenciaram a introdução da algaroba no Brasil e do milho híbrido na França. A produção de conhecimentos científicos, orientados à inovação nos processos de produção agrícola, representa um esforço de planejamento e a intensificação do controle de dinâmicas econômicas e sociais, que colocaram diferentes atores sociais em interação, e, portanto, potencialmente capazes de produzir efeitos não controlados e consequências não planejadas de modernização produtiva.

Palavras-chave: Modernização da agricultura. Dinâmicas Institucionais. Processos sociais.

Abstract: The purpose of this article is to analyze the dynamics that influence the introduction of algaroba in Brazil and hybrid corn in France. The production of scientific knowledge, oriented to innovation in agricultural production processes, represented a planning effort and the intensification of control of economic and social dynamics that put different social actors interacting, and therefore potentially capable of producing uncontrolled effects and consequences unplanned production modernization.

Key words: Modernisation of agriculture. Institutional dynamics. Social processes.

Résumé: Le but de cet article est d'analyser les dynamiques qui l'introduction l'algarobe au Brésil et le maïs hybride en France. La production de la connaissance scientifique, axée sur l'innovation dans les processus de production agricole a représenté un effort de planification et de l'intensification du contrôle des deux dynamique économique et sociale, processus qui mettent les différents acteurs sociaux en interaction, et donc potentiellement capables de produire des effets incontrôlés et des conséquences imprévues de la modernisation productive.

Mots-clés: Modernisation de l'agriculture. Dynamiques institutionnelles. Processus sociaux.

Resumen: El objetivo de este trabajo es analizar la dinámica que influyeron en la introducción de algarrobo en Brasil y el maíz híbrido en Francia. La producción de conocimiento científico, orientado a la innovación en los procesos de producción agrícola representó un esfuerzo de planificación y la intensificación del control de las dinámicas económicas y sociales que ponen los diferentes actores sociales en la interacción, y por lo tanto, potencialmente capaz de producir efectos no controlados y consecuencias no planificadas de modernización de la producción.
\end{abstract}

Palabras clave: Modernización de la agricultura. Dinámica institucional. Procesos sociales.

\section{INTRODUÇÃO}

No livro Ciência em Ação, publicado em 2000, Bruno Latour propõe o exercício de seguir cientistas em suas práticas profissionais como um desafio epistemológico, o que ofereceu inúmeras possibilidades de construir chaves interpretativas acerca do papel político da ciência, mas também de como são produzidas determinadas crenças em torno da chamada tecnociência. Simultaneamente subjetiva e objetiva, a ciência produz fatos e artefatos, os quais, ao serem narrados, são descritos, explicados na forma de artigos e comunicações científicas, que são banhadas pelo elixir iluminista da verdade inquestionável e da solução de problemas das comunidades humanas e do mundo físico. Os casos empíricos apresentados aqui são exemplares de como o discurso produzido por cientistas

* Universidade Federal de Campina Grande, Campina Grande, Paraíba, Brasil. 
autonomiza-se dos seus autores, , além de elicitar crenças e expectativas diversas, o que gera processos e dinâmicas não controladas e não planejadas.

Trabalharemos neste artigo, a partir de um quadro geral que envolve dinâmicas sócio-históricas, econômicas e científicas, que influenciaram a introdução da algaroba (Prosopis Juliflora) no Brasil e do milho híbrido na França, enquanto estratégias de inovação técnica, modernização e dinamização das atividades agrícolas em meados do século XX. Utilizaremos o recurso da aproximação descritiva com o intuito de evocar processos, que, face aos distintos cenários históricos e espaciais, não teriam, aparentemente, elementos comuns que se prestassem à análise comparativa. Consideramos, nos dois casos, a trajetória de instituições, bem como dos atores que as representam, por entender que as escolhas e decisões tomadas resultam de embates, negociações e compromissos entre agentes, assim como de disputas em torno de ideias e de poder, nem sempre visíveis.

Adotamos a categoria da figuração, conforme proposta por Elias (1981), como chave de análise para refletir sobre aspectos presentes nos dois casos estudados, os quais remetem a processos mais gerais de inovação, modernização, desenvolvimento e políticas públicas nos dois contextos mencionados.

A noção de figuração compreende um sistema social de tamanho variável, no qual os indivíduos vivenciam situações de interdependência, mas também de concorrência social, segundo um equilíbrio de tensões mais ou menos estáveis (DÉCHAUX, 1993). É evidente que essas relações não ocorrem no vazio, mas num campo social particular, no qual as ações são interdependentes e se influenciam mutuamente.

A experiência de introdução da algaroba no Brasil e do milho híbrido na França, ambas consideradas estratégias de modernização levadas a efeito na década de 1950, consiste em casos sob muitos aspectos interessantes para analisar o impacto das decisões e das mudanças sociais decorrentes destas. De um lado, percebe-se que a produção de conhecimentos científicos voltados à inovação representa a lógica planejada e aparentemente controlada dos casos; por outro lado, governos, gestores, proprietários rurais (pequenos, médios e grandes) e empresários, são atores cujas interações produzem efeitos não controlados e, por vezes, não intencionados. Nos casos da algaroba e do milho, as figurações formam uma realidade que, longe de serem invariantes, se movimentam assumindo posições, no sentido de materializar uma aliança entre esforços de modernização e progresso.

Os dados que inspiraram as reflexões apresentadas nesse artigo foram obtidos a partir de pesquisa bibliográfica e documental. Apenas no estudo da algaroba nos apoiamos também em entrevistas semiestruturadas com interlocutores que têm convivido com a presença da espécie em suas áreas produtivas. $\mathrm{O}$ trabalho de pesquisa buscou mapear as experiências da introdução da algaroba no Brasil e do milho híbrido na França como realidades sociais e históricas específicas, produzindo consequências singulares em cada um dos países, ao mesmo tempo em que focaliza elementos comuns e os efeitos destes nos projetos de desenvolvimento em curso nos dois cenários analisados.

As reflexões foram direcionadas pela análise das dinâmicas institucionais que produziram questões do tipo: quais argumentos legitimam a algaroba e o milho híbrido como estratégias para impulsionar a modernização e promover o desenvolvimento nos dois cenários mencionados? O que explica a inversão discursiva, que, nas décadas de 1980 e 1990, dividiu opiniões e transformou tanto a algaroba, quanto o milho híbrido em vilãs de ações enunciadas como destinadas a modernizar a agricultura no Brasil e na França?

Ambas as alternativas se apoiaram em soluções exógenas como estratégias para modernizar e desenvolver a agricultura, representando formas de dominação da natureza, capazes de produzir espaços e relações homogêneas, necessárias ao progresso e a certo modelo de desenvolvimento. Contudo o estudo dos casos revelou que a introdução das espécies citadas produziu resultados não previstos, os quais se relacionam a figurações espaciais e sociais significativamente afetadas, cujos contornos são avaliados de modo negativo 50 anos depois.

Cada parte do artigo consistirá em uma tentativa de analisar as figurações no momento da introdução das espécies e no desdobramento temporal dela, a mobilização 
de discursos e representações construídas pelos atores a respeito da modernização que ela representava, identificando contradições, polarização entre categorias a exemplo da diversidade e homogeneidade; local e global; moderno e atrasado. Finalmente, trabalhamos com um quadro de análise que instiga o questionamento de situações construídas no interior de jogos relacionais que institucionalizam ideias-saber as quais dão força tanto à reprodução quanto à mudança socioespacial e técnica (BOURDIEU, 2000; ALPHANDÉRY; SENCÉBÉ, 2009).

\section{CONFIGURAÇÃO E TRAJETÓRIA: INO- VAÇÃO TÉCNICA E MODERNIZAÇÃO}

A relação entre articulação, interdependência e dominação, através de ideias-força, formou um quadro interpretativo, que conduziu, tanto no caso do Semiárido do Nordeste do Brasil, quanto da região de Bresse na França, a introdução de espécies exóticas como estratégia de inovação técnica para impulsionar a modernização de setores da economia, em particular da agricultura, e em regiões tidas como precárias, fragilizadas e que apresentavam pouco ou nenhum dinamismo econômico.

Processos de inovação tecnológica na agricultura já estavam em curso em outros países, especialmente nos Estados Unidos da América (EUA). Esse processo de replicação de experiências de inovação tecnológica foi denominado de indústria do progresso técnico (BERLAN, 1987). Assim, a experiência com a algaroba, introduzida no Semiárido brasileiro, é mais um produto dessa indústria. Nesses casos, a ideia-força consistia em trazer uma espécie exógena para salvar o Semiárido da pobreza. Discurso embasado numa visão iluminista do saber - o saber científico. As vantagens que a espécie Prosopis Juliflora apresentava no primeiro momento eram, verdadeiramente uma invenção do mundo moderno - reflorestamento com algaroba, ração de algaroba, café de algaroba, cachaça de algaroba, fécula de algaroba.

As primeiras experiências com algaroba de que se têm conhecimento no Brasil, antes dos anos 1950, não eram planejadas, nem controladas. Este é um ponto de diferença em relação ao milho híbrido, que, desde o início, foi um processo controlado pela ciência e conduzido por uma aliança entre a pesquisa pública e gestores e executores das políticas agrícolas na França. Desde o fim da I Grande Guerra, ficou evidente que o problema agrícola da França não podia mais esperar, logo em 1947 é lançado o primeiro plano de modernização e equipamentos, o Plan Monnet, e, em 1948, os EUA lançam o Plano Marschall ${ }^{1}$, que reforçou as orientações produtivistas do Plan Monnet. O papel determinante do Estado manifesta-se em nível das grandes orientações econômicas, mas também dentro do enquadramento da produção. Estava claro, sobretudo a partir das eleições de 1951, que o objetivo do estado francês era conquistar um espaço reconhecido no mercado mundial. A solução seria integrar plenamente a produção ao sistema econômico global (GERVAIS; JOLLIVET, 1987).

Na sequência desse momento, em 1950 o ministro da agricultura francês publicava uma nota sobre a organização europeia dos mercados agrícolas, declarando que, após negociações internas e externas, a agricultura francesa encontrara equilíbrio, simultaneamente demandando recursos ao mercado interno e assegurando o crescimento da indústria, através do progressivo aumento da compra de tratores, máquinas agrícolas e produtos químicos.

No Brasil, em 1942, em visita de estudos ao Nordeste, o Professor Griffing, renomado pesquisador norte-americano, especialista na área de genética molecular e diretor da Escola de Agronomia de Viçosa, MG, ficou bastante impressionado com a situação do rebanho no período de estiagem, quando as forrageiras herbáceas secavam totalmente, restando apenas as fibras. Os animais necessitavam de uma forrageira em condições de suprir o déficit energético e proteico. Sendo assim, o Professor Griffing enviou sementes de algaroba para o agrônomo Clodomiro Albuquerque do Instituto Agronômico de Pernambuco (IPA), e

\footnotetext{
${ }^{1}$ Sobre o Plano Marschall foi um plano de reconstrução desenvolvido para permanecer em operação por quatro anos fiscais a partir de julho de 1947. Durante esse período, algo em torno de US\$ 13 bilhões de assistência técnica e econômica - equivalente a cerca de US\$ 132 bilhões em 2006, ajustado pela inflação foram entregues para ajudar na recuperação dos países europeus que juntaram-se à Organização Europeia para a Cooperação e Desenvolvimento Econômico (GASPARETTO JÚNIOR, s.d.).
} 
as primeiras mudas ficaram sob os cuidados do agrônomo Lauro Bezerra, também do IPA. O agrônomo Lauro Bezerra, ao realizar experimento com a espécie no município de Serra Talhada, PE, descartou as mudas alegando que não queria introduzir mais espinhos na região. Essa primeira tentativa de introdução da espécie Prosopis Juliflora fracassou em pouco tempo de teste (AZEVEDO, 1982).

Ao passar casualmente por Angicos, RN, em 1950, Azevedo (1982) aproveitou para conhecer a fazenda experimental da Machine Cotton, onde estava sendo realizado um experimento de cruzamento do algodão Mocó com o algodão Pema. E, ao observar a paisagem, percebeu que havia plantas com folhagens verdes mesmo no mês de novembro, quando já não chove mais e a vegetação está completamente seca, fato que chamou a atenção do pesquisador. Senhor King, diretor da fazenda, informou que se tratava da algarobeira, originária do Peru, que tinha sido indicada para alimentação do rebanho, porém não permitiu o acesso às plantas.

Meses depois, o substituto do Senhor King, o Senhor Wallace, permitiu o acesso à planta como também ao relatório em que o Senhor Harland aconselhava à introdução da algarobeira como planta forrageira. Em 1950, iniciou-se no Rio Grande do Norte um estudo científico com essa planta, procurando observar seu comportamento quando submetida a fatores ecológicos e aos variados tipos de solo. Com os primeiros resultados bastante animadores, em virtude da velocidade de crescimento $(1 \mathrm{~m} / \mathrm{ano})$, as mudas foram levadas e distribuídas nos municípios do Semiárido para arborização. Em 1953, Azevedo enviou material ao professor Arturo Burkart, do Instituto Darwinion, na Argentina, autor de uma monografia do gênero Prosopis Juliflora e então ficou constatada a existência de uma única espécie Prosopis Juliflora DC.

No início da década de 1950, as experiências com algaroba passaram a ser mais sistematizadas, planejadas agora em um contexto político marcado pelo desenvolvimentismo. Pesquisadores ligados ao Ministério da Agricultura, Ministério do Interior e do Instituto Brasileiro de Desenvolvimento Florestal (IBDF), continuaram fazendo levantamentos bibliográficos e observações sobre o comportamento da algarobeira, velocidade de crescimento, apreciação pelo gado e idade de início de frutificação. Os resultados das primeiras pesquisas indicavam a algarobeira como produtora de excelente madeira de lei e enorme capacidade de resistência à seca (GOMES, 1961).

Para recuperar o contexto histórico do caso Francês, como referência bibliográfica, tomamos a obra de Henry Mendras, Le Fin des Paysans, de 1984. Nesse texto, Mendras analisa o processo de modernização da agricultura na França, particularmente os aspectos que levaram à introdução do milho como espécie inovadora, Mendras lembra que a cultura alimentar do país até o século XIX era basicamente o pão, acompanhado de qualquer outro legume e leite. A sociedade camponesa das regiões de Bresse e do Massif Central era simples, marcada por relações pessoais, produtoras de uma cultura viva, coletiva, restrita e autônoma.

Antes do século XIX, outras experiências devem ser lembradas, como estratégia para modernizar a agricultura na França, a exemplo do moinho à água. Mendras (1984, p. 50) assinala que "em todos os casos, a lógica da sociedade industrial modifica, não apenas a economia rural, mas provoca alterações significativas também no sistema de valores e na visão de mundo da sociedade englobante". Estudiosos da sociedade rural francesa concluíram que as mudanças ocorridas em períodos precedentes não destruíram o equilíbrio existente, sobretudo o equilíbrio natureza e sociedade. Dado que pode ser exemplificado com a introdução do milho na Alsace, Sudoeste da França, nos séculos XVII e XVIII, quando o milho ajudou a equilibrar o consumo do trigo.

Nos anos 1950 do século XX, o milho híbrido saía dos EUA e desembarcava na França, pelas mãos do Institut National de la Recherche Agronomique (INRA). As espécies F2 e F7 seguiram para a região de Bresse, onde já estava implantado o milho tradicional, ou o milho do país. A chegada do corn-pickers (colheitadeiras) movimentou radicalmente a cultura tradicional ; o fato é que os primeiros híbridos eram mais precoces e mais resistentes à seca, possibilitando um cultivo mais denso e com melhor rendimento em termos produtivos e de renda (HIRCZAK ; MOLLARD, 2005). O milho híbrido foi implantado em 
um contexto de discursos interdependentes, complementares e concorrentes.

No caso da introdução do milho na França, o conhecimento não pôde ser desconectado do projeto mais amplo de desenvolvimento levado a cabo à época pelo estado francês, muito menos da figura de certos beneficiários, empresas de sementes e agricultores. A tese de Jean-Pierre Berlan (1987), intitulada D'un changemente technique: les mytes du maïs hybride, apresenta uma descrição do caminho trilhado pela pesquisa sobre inovação técnica, a partir do milho híbrido. Nas primeiras linhas da tese, o autor utiliza a seguinte metáfora: a mudança técnica ou o mistério da caixa preta. No pós-guerra, o discurso de que o progresso técnico aconteceria por meio de um milagre, através de um símbolo exógeno tornou-se uma ideia-força, no meio técnico-científico e entre os agentes das políticas públicas para modernizar a agricultura. Embora houvesse divergências, quanto ao método de apropriação desta ideia, políticos, cientistas e governantes defendiam que o progresso técnico é exógeno e que os economistas não podiam fazer mais que estudar os seus efeitos; outros afirmavam que seria necessário aperfeiçoar o modelo precedente e endogeneizar a mudança técnica.

As ações de incentivo à implantação da algaroba foram orientadas por dois objetivos: propiciar alimentação para os rebanhos e cobrir as extensas áreas desnudas. Por sua vez, o esforço para legitimar a implantação do milho híbrido na França era evidenciado no discurso de que o híbrido seria cultivado da mesma maneira que o milho tradicional, que esta seria uma cultura especulativa, destinada à venda e garantiria uma rentabilidade três vezes mais elevada que o trigo (MENDRAS, 1984).

O reforço da ciência, no que se refere ao milho, ecoava especialmente dos EUA. O professor Paul Mangelsdorf (1951) da Universidade de Harvard, em seu artigo Hybrid Corn afirma que o milho híbrido é uma das criações humanas, que mais movimentaram a biologia aplicada no século XIX. A mudança genética que deu origem ao milho híbrido revolucionou a cultura do milho nos EUA, e o milho híbrido produz muito mais e transforma tudo que ele toca. Nos EUA a experiência com o milho híbrido confirmou a importância da liberdade na pesquisa técnica e aplicada, como um campo autônomo, produzindo dinâmicas, independentemente do contexto histórico e político.

Também o relatório Grilliches (1958), seguido em diferentes experiências de pesquisa realizadas pelos pesquisadores do INRA, apresenta um cálculo concernente à relação custo benefício do milho híbrido de que, para cada 1 dólar investido no milho híbrido, o retorno seria de 7 dólares; de outra parte, esse benefício poderá ser repassado ao consumidor, sobre a forma de preço baixo, decorrente do crescimento da produção. Consequentemente, o custo desse melhoramento implicava mudanças ambientais e sociais que não seriam da mesma maneira controláveis e mensuráveis, a exemplo dos agricultores de Valée de Nay (França), para quem a relação com o mundo exterior foi uma sequência de experiências não exitosas em decorrência da modernização da agricultura através do milho híbrido.

Em ambos os casos, o discurso científico corroborou para mostrar a viabilidade das espécies para minimizar o problema da escassez de alimento para os animais, para aumentar a produção leiteira; provavelmente favoreceria a urbanização e a industrialização de certas regiões, além de reduzir a pressão sobre outras espécies, na medida em que, pouco a pouco, as espécies exógenas seriam incorporadas à cultura alimentar.

\section{DISCURSOS E INVERSÕES: DO PA- RAÍSO AO PURGATÓRIO}

Nessa configuração inovadora, os atores tanto são indutores, como induzidos aos processos na medida em que as práticas sociais se entrelaçam provocando mudanças. Faz-se aqui referência a atores sociais que se situam em campos próximos mais distintos, cientistas, gestores públicos, sindicatos, associações etc. Contudo, em nenhum momento desse processo, houve questionamentos aos limites das intervenções científicas ou políticas. As mudanças que ocorreram nas sociedades, brasileira e francesa, e no meio ambiente, em decorrência desses arranjos produziram práticas sociais multiformes, que explicam mudanças, mas também movimentos de resistência. 
A incorporação da algaroba no Semiárido nordestino ocorreu em um contexto no qual a criação de animais era realizada de forma extensiva, prática que ainda perdura e é caracterizada pelo livre pastoreio dado que, face ao potencial forrageiro da vegetação nativa, exige grandes extensões para a solta do gado. Inicialmente, a missão da algaroba, e de seus defensores, era minimizar a vulnerabilidade dos rebanhos do Semiárido em relação aos recursos florestais, uma vez que estes poderiam garantir a alimentação dos animais durante as estiagens, sem contar com a riqueza que esta representava no fornecimento de lenha e estacas.

Dentro do cenário desenvolvimentista, os discursos apresentavam a algaroba como uma espécie que iria salvar o Semiárido nordestino. Os projetos produtivos que utilizavam a algaroba (Prosopis Juliflora) foram incentivados pelos agentes estatais e técnicos com a finalidade de recuperar áreas degradadas, de reflorestamento, de ser uma alternativa de alimentação para os animais e alternativa econômica através dos múltiplos usos da madeira. A algaroba implantaria no Nordeste um modelo capaz de integrar e desenvolver essa região, pelo cercamento dos campos - técnicos e políticos.

Reforçando o discurso dos agentes governamentais, a imprensa ocupou um lugar importante na divulgação de um discurso de salvação como bem detalha (BURNETT, 2007). O ministro da agricultura Romero Costa, em sua primeira entrevista à imprensa, disse ao Jornal do Brasil, em 9 fevereiro de 1961, que pretendia fazer o reflorestamento de todo o sertão e agreste do Nordeste com algaroba, uma árvore resistente às secas (SILVA, 2000). Os jornais de diferentes Estados destacaram a sua visita a vários municípios do Nordeste, sempre com apoio local da Igreja, para dar início ao plantio de 100 milhões de mudas.

Atualmente, observamos que o jogo discursivo gestado na aliança entre inovação e progresso se apropria e usa a ciência para iluminar a realidade, mas também para encobrir verdades. Em 1955, o agrônomo Renato de Farias, baseado em estudos sobre a experiência americana com uma das várias espécies de algaroba, declarou que tal espécie era invasora, essa declaração não teve nenhuma repercussão na época. A aliança entre técnicos, agentes governamentais e elites políticas e agrárias já havia consagrado simbólica e materialmente a algaroba como estratégia de desenvolvimento.

Superado o período áureo dos incentivos governamentais, praticamente duas décadas após a introdução da algaroba, outro discurso ganhava força, o mito da magia negra; a algaroba passaria então a ser considerada uma erva daninha, responsabilizada por causar danos incalculáveis ao ambiente, como secar os solos e os mananciais, além de causar doenças nos rebanhos bovinos, como o mal da cara torta ${ }^{2}$ e a língua-de-pau ${ }^{3}$. Com isso, os grandes agricultores iniciaram um processo de exploração e corte das árvores que ameaçavam a extinção da espécie. Estava declarado tratar-se de uma vilã.

No Brasil e na França, os processos de modernização da agricultura, representados pela introdução da algaroba e do milho híbrido, impulsionaram mudanças e resistências, que ecoaram simbolicamente através de discursos favoráveis e contrários. Mendras (1984), analisando os argumentos adotados para justificar os locais para realização das experiências com o milho híbrido, ressalta que os pesquisadores e o governo defendiam que o Sudoeste da França apresentava as condições ideais, uma região habitada por camponeses com fortes laços de vizinhança, o que tornaria o processo de difusão das práticas e dos tratos culturais mais eficazes, e uma juventude que participava ativamente de movimentos da Jeunesse Agricole Chrétienne, a qual apresentava disposição para assistir reuniões, sendo facilmente atraídos pelo discurso da modernidade, através da inovação.

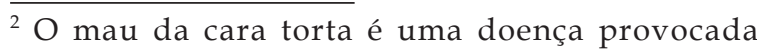
pela ingestão excessiva ou exclusiva das vagens da algarobeira é uma doença que atinge bovinos e tem o nome popular de cara torta devido ao desvio lateral de cabeça que o animal realiza para manter o alimento na boca durante a mastigação.

${ }^{3}$ A actinobacilose, também conhecida como língua de pau ou língua de madeira, é uma doença infecciosa, não contagiosa, crônica e granulomatosa que acomete os tecidos moles de bovinos, resultando no aparecimento de piogranulomas com presença de drusas no seu interior (MELDAU, s.d.).
} 
No momento da V Republique ${ }^{4}$, o jogo discursivo mudou completamente. Com o General Charles de Gaulle tinha-se um governo de direita, para quem a política agrícola não passava de um apêndice da política econômica. Os profissionais da agricultura e os próprios agricultores, bem como os sindicatos de agricultores, não conseguiam pautar suas demandas, fazendo com que os grupos de agricultores de esquerda, que historicamente mantiveram uma postura anticlerical, embora desejassem o desenvolvimento das atividades rurais, começassem a pressionar o governo, denunciando o imperialismo americano. Outros agricultores, defensores do milho tradicional, também aderiram aos discursos de esquerda e foram considerados conservadores pelos defensores do milho híbrido.

O cenário político claramente polarizado, de um lado o governo e os pesquisadores, do outro lado os agricultores, concorreu para a transformação dos discursos acerca da modernização da agricultura, representada pelo milho híbrido (SARDAN, 1995, p. 85-86). Para técnicos, economistas e agrônomos, o milho híbrido era extraordinariamente vantajoso. Entre os agricultores, era evidente o temor em relação ao desconhecido, por isso mesmo continuavam plantando o milho tradicional. Não havia dúvidas acerca da superioridade produtiva do milho híbrido. Mas, pouco a pouco, o argumento da rentabilidade começava a perder força entre os agricultores, tendo em vista que o milho híbrido era também mais exigente, em termos de trabalho, tratos culturais e maquinários, comparado ao milho tradicional.

As ações implementadas pelos extensionistas difundindo o rendimento do milho híbrido não foram suficientes para convencer os agricultores a correr o risco. Então, se

\footnotetext{
${ }^{4}$ É o atual regime republicano francês, que entrou em vigor em 1958 do século XX, tendo sido o General Charles de Gaulle indicado como primeiro presidente desse regime. Dentre os objetivos econômicos e financeiros da Cinquième République, estava a agricultura. Para o General de Gaulle, a agricultura e a estrutura produtiva, incluindo as parcelas agrícolas, estavam arcaicas, e os custos dos produtos de origem agrícola eram extremamente elevados. O Presidente assinalava que, nesses termos, a agricultura era um obstáculo à expansão econômica da França, retardando o desenvolvimento e a expansão do comércio e da indústria (GERVAIS; JOLLIVET, 1987).
}

um vizinho estava ainda refletindo sobre a possibilidade de aderir ao milho híbrido, logo chegava outro que oferecia sementes para começar a produzir. O conflito entre os inovadores e aqueles que resistiam às ideias se instalava. Ante o conflito, a posição do estado era clara em apoiar os bons agricultores, através da pesquisa e da assistência técnica. A lógica era fazer com que os agricultores tradicionais quisessem imitar os agricultores modernos como uma representação de confiança, "a autoridade pessoal e social particularista de um pai é substituída pela autoridade universalista da ciência" (MENDRAS, 1984, p. 66).

Assim como no caso da algaroba, na experiência com o milho híbrido, os discursos e os atores portadores destes se dividiam. $\mathrm{O}$ argumento da superioridade produtiva se apoiava em comprovações científicas e estudos que se pretendiam conclusivos. Em oposição ao que afirmava o governo e os cientistas, tem-se a experiência prática, individual ou familiar, a exemplo de enquetes realizadas com agricultores que aderiram ao cultivo do milho híbrido. Ao comparar a experiência de cultivo do milho tradicional com o milho híbrido, os agricultores concluíram que o milho do país é branco, enquanto o milho híbrido é amarelo; que o milho híbrido não alimenta satisfatoriamente as aves; que o milho híbrido provoca doenças no fígado dos animais. Uma agricultora afirmou que, "a gente dá milho híbrido às galinhas, 2 horas depois elas estão em torno da gente procurando comida" (MENDRAS, 1984, p. 153).

O julgamento e a condenação das duas espécies - algaroba e milho - em contextos distintos ensejam figurações que produzem diferentes maneiras de circular bens, recursos e capitais diversos. Tanto no Brasil como na França, foi, sem dúvida, o Estado quem assumiu por estratégias diversas a direção do processo de modernização da agricultura, empreendeu novas técnicas, mecanizou e facilitou o acesso ao crédito. Entretanto, na França, a modernização foi acompanhada de um conjunto de reformas estruturais, especialmente no campo da pesquisa agronômica.

No Semiárido do Brasil, a modernização foi reduzida a experiências de inovação pontuais, criação de perímetros irrigados, implantação da algaroba, incentivos à capri- 
nocultura, contudo sem jamais tocar, na questão da estrutura fundiária, na concentração de rendas, na profissionalização da agricultura. $\mathrm{Na}$ França, a aliança entre o Estado e os jovens profissionais da agricultura, quer dizer os jovens do Centro Nacional dos Jovens Agricultores (CNJA), compôs a base de apoio do governo do General Gaulle para elaborar as leis de orientação da agricultura entre 1960 e 1962. No Brasil, a política pública de incentivo à introdução da algaroba esteve fortemente atrelada às oligarquias locais.

Analisando o caso do milho híbrido na França, percebe-se que esse processo foi extremamente vantajoso para as empresas que detinham o monopólio da produção de sementes, Limagrain e Monsanto; para estas a inovação com os híbridos compensou, porque aumentou a dependência dos agricultores, uma vez que estes necessitavam de sementes selecionadas para o plantio. Assim, tal processo apresenta características modernas de mercado que favorecem formas de concorrência acessíveis apenas às grandes empresas, as quais dispõem de meios eficazes de desenvolver a ação publicitária.

Como lembra Latour (2000), seguir os cientistas é uma chave para compreender a ação da ciência. A pesquisa diferencia a qualidade, eleva o crescimento, constrói e reforça o discurso midiático que possibilita às empresas de pesquisa ter sempre algo atrativo para oferecer. A investigação de dinâmicas, com vistas ao desenvolvimento, deve levar em consideração os custos com a pesquisa. Evidentemente que não é o cálculo direto que interessa, e sim os postulados e a capilaridade das descobertas, o alcance das informações. Na França, depois de 20 anos desenvolvendo pesquisas com híbridos, o INRA colocava à disposição um número significativo de variedades comerciais. Após 1982, as vantagens da técnica híbrida justificam o custo da pesquisa pública. O INRA não desenvolveu apenas um tipo de milho híbrido e não atende apenas a um mercado exclusivo.

Entre os resultados não previstos no caso da algaroba, as mudanças discursivas ainda que sem comprovação científica, favoreceram outras estratégias como a extração da madeira, que deu origem a uma rede de comercialização. É factível a política de incentivos ao desmatamento da algaroba, sob o argumento de que a dificuldade de manejar faz com que a espécie invada solos férteis e desnudos, provocando um desastre ambiental sem proporções. O desmatamento, portanto, aparece como a única solução, ainda que comprometa o equilíbrio ambiental do bioma caatinga, cujas condições físicas apresentam níveis avançados de desertificação.

$\mathrm{O}$ retorno econômico que a algaroba oferece no plano imediato às populações locais faz da espécie uma alternativa econômica, enquanto para os grandes proprietários o futuro mais certo para a algaroba é a erradicação, através do corte e da retirada da madeira. $O$ fato é que os grandes legitimaram e modernizaram também suas narrativas, através do discurso ambientalista que sugere a preservação e conservação do bioma natural e a devastação de espécies exóticas. Já estudos realizados pela Empresa Brasileira de Pesquisa Agropecuária (EMBRAPA) Semiárido, sugerem o manejo como estratégia viável para equilibrar as vantagens econômicas e o problema ecológico, na medida em que possibilita a utilização desta como fonte de energia e de alimentação humana e animal (LIMA, 2005). Para os representantes do Instituto Brasileiro do Meio Ambiente e Recursos Naturais Renováveis (IBAMA) a preocupação atualmente é com as espécies nativas, não importando o exótico, nem como recurso natural, nem como alternativa de renda para as populações mais vulneráveis.

\section{HOMOGENEIZAÇÕES E RECOMPOSI- ÇÕES ESPACIAIS}

Processos de inovação são dotados de produtos e efeitos esperados e também de consequências inesperadas. Adotar a inovação como estratégia para impulsionar mudanças é um processo que remete à produção de novas institucionalidades e de regras sociais, assim como a um sistema de desigualdade tradicional. Uma inovação pode ainda implicar uma redistribuição de cartas que resultam na emergência de novas elites, em novos modos de relacionar-se com os recursos naturais e até mesmo na recomposição de espaços (SARDAN, 1995). Nas experiências da algaroba e do milho híbrido, muitos elementos podem ser destacados como produtos esperados e resultados não esperados. 
A discussão em torno da algaroba no Nordeste atravessou diversas fases, como dissemos: de espécie salvacionista à praga. Atualmente são usados diferentes qualificativos para se referir à árvore. De fato, ao contrário do milho híbrido, as reconfigurações produzidas pela algaroba no curso de 50 anos são diversas, de modo geral, a população local se acostumou com a presença da algaroba, de tal maneira que o diferente, o exótico tornou-se familiar, do lugar. Não há no Brasil florestas de algaroba, portanto trata-se de uma espécie que, pouco a pouco, se incorporou ao bioma e à paisagem.

Para outros, sobretudo os grandes proprietários, que se beneficiaram no primeiro momento dos projetos e financiamentos públicos, produzem um eco inflamado e hegemônico contra a algaroba. Do lado oposto, para os pequenos agricultores e assentados da reforma agrária, a algaroba é tida como a salvação na época de estiagem, pois acaba sendo o único recurso disponível para alimentar os animais e complementar a renda familiar com a venda da vagem. Segundo Moreira (1999), o discurso ecológico mais contemporâneo adiciona elementos à concepção dominante, de que os recursos naturais, ao gerarem renda para manter a família, fazem uso sustentável desses mesmos recursos.

Objetivamente a algaroba foi introduzida há mais de 40 anos para fins forrageiros e de reflorestamento, atualmente ocupa grandes extensões e terras em todos os estados do Nordeste, com estimativas de ocupar mais de 500 mil hectares. O quadro de ocupação da algarobeira no Nordeste corrobora para o fato de ser esta uma alternativa econômica, em virtude dos usos diversos dos derivados da espécie em diferentes setores da economia regional. Atualmente estudos realizados, especialmente pela EMBRAPA Semiárido, sugerem o manejo como estratégia viável para equilibrar a relação entre vantagens econômicas e problema ecológico, possibilitando a utilização da vagem de algaroba como fonte energética para alimentação humana e animal (LIMA, 2005).

Outro dado incontestável é a produtividade da algaroba, com relação à produção de vagens estima-se que esteja em torno de 2 a 8 t/ano, dependendo das condições edafoclimáticas da região e manejo adotado. Da produtividade em madeira, em rotação de 10 a 15 anos, se espera produtividade de lenha de 50-100 t/ ha. Segundo estimativas de Nobre (1982) em uma área racionalmente explorada, a produtividade da algarobeira por hectare/ ano está entre 100 a $200 \mathrm{~m}^{3}$ para lenha, 500 a $700 \mathrm{~kg}$ para carvão; 500 a 700 unidades de estacas e 200 a 250 unidades de mourões.

As formas de plantio da algarobeira também foram profundamente alteradas, atualmente o consorciamento da algaroba é a forma mais usual. A prática do consórcio da algaroba com a palma forrageira (Opuntia Ficusíndica) é bastante adotada pelos pequenos e médios agricultores; Outra associação bastante comum é a algaroba com o capim búfel (Cenchrus Ciliares), associação em que a algaroba melhora a qualidade do capim em termos de concentração de proteína bruta.

A utilização da algaroba como forragem é inegável, sendo um dos mais importantes suplementos na alimentação de bovinos, ovinos, caprinos, muares e outros animais. Por causa da palatabilidade, a vagem é mais consumida, mas as ramas também servem de alimento em casos de extrema necessidade, geralmente colocadas para o animal na forma de feno, trituradas e misturadas em pequenas proporções com outras forrageiras. Além disso, estudos indicam que o plano de manejo sustentado da algarobeira pode ser uma alternativa viável para conviver com a espécie, uma vez que os levantamentos realizados têm demonstrado que o processo de invasão ocorre em sua maioria em áreas ao redor de rios e riachos, permanentes ou não e, sem nenhuma forma de manejo (TAYLOR, 1969; HIDALGO, 1996).

A Fazenda Reunidas Rio de Contas Ltda. (RIOCON), com sede em Salvador, BA, vem desenvolvendo projetos de integração, através de cadeias produtivas sustentáveis, caprino, ovinos e algaroba, tendo como foco principal, a inserção social dos pequenos e médios produtores rurais das regiões onde atua. Para a RIOCON, a algaroba é uma excelente alternativa econômica social, ambiental, política e cultural para a região. Um dado relevante sobre o potencial da algaroba é o fato de que só no Médio-Baixo São Francisco, na divisa da Bahia com Pernambuco, já são 30 mil hectares plantados, elencando uma cadeia produtiva que engloba três vertentes: 
florestal (energia limpa, carvão vegetal), ração animal (farelo) e alimentação humana (farinha e goma).

O milho híbrido, implantado na região de Bresse, substituiu o milho tradicional e contribuiu para a diminuição do valor econômico do trigo. Depois, o milho híbrido mudou o sistema de rotação e integração de culturas, criando uma situação em que muitos agricultores não conseguiram se integrar. Essa realidade, aliada à lei aprovada em 6 de julho de 1964, que visava à aceleração da seletiva modernização, definiu os princípios e as modalidades do regime contratual na agricultura; em suma, um apoio explícito a organizações que integram interesses da indústria, da agricultura e do comércio (GERVAIS; JOLLIVET, 1987). Esses elementos contribuíram para a transformação de pequenos produtores (agricultores livres) em proletários, sub-explorados, favorecendo o aparecimento de grupos de agricultores neocapitalistas.

Enfim, o esforço de modernização que teve início nos anos de 1950, hoje revela uma diferenciação crescente entre os espaços produtivos. Tais descontinuidades se revelam na inserção dos atores no mercado, mas também nas diferenças entre os territórios rurais. A região de Bresse, antes dominada por uma agricultura camponesa, hoje se apresenta como um território dinâmico e competitivo. Um território de florestas homogêneas e artificiais, formadas pelos vastos campos de milho híbrido, sendo a monotonia do verde quebrada pelas enormes máquinas, colheitadeiras, sementeiras e pulverizadoras.

A artificialidade dos campos de milho híbrido e as representações discursivas dos consumidores em relação à introdução desse cereal como alternativa alimentar reforçam a representação do milho, sempre como algo exótico e estranho. Contudo as controvérsias científicas entre governo e sociedade permanecem. Mas o fetiche da modernização é cada vez mais sedutor, através de forte apelação à seleção e ao melhoramento de plantas como alternativa para o problema da insegurança alimentar. Contraditoriamente, as plantas transgênicas que ocupam hoje milhões de hectares na França são, na maior parte, destinadas à alimentação animal, a exemplo do milho e da soja. O resultado dessa estratégia de inovação suplantou a paisagem e as culturas tradicionais, favoreceu o surgimento de oligopólios, como as empresas cerealistas e as agroquímicas, e eliminou os agricultores locais.

Com a política de incentivo, que vigorou nos anos 1960, 1970 e 1980, mediante o financiamento público, subsidiado, consolidaram-se os ganhos e a distribuição dos resultados do progresso técnico, entre os proprietários de terra. Principalmente no que se refere à acumulação de poder e capital, materializado cada vez mais na continuidade da propriedade da terra, isso tem despertado o interesse de setores privados que se apropriam dos ganhos do progresso para manterem o status quo.

\section{CONSIDERAÇÕES FINAIS}

Refletir sobre as experiências do milho e da algaroba, a partir de um quadro de mudança social, vis-a-vis o desenvolvimento, sugere que, entre os países do novo e do velho mundo, não há mais que o Oceano Atlântico. As estratégias para consolidação do capitalismo americano no contexto do pós-guerra assumiram faces e discursos multiformes que figuraram de certa maneira entre os mediadores em nível global e, de maneira completamente diferente, entre os sujeitos em nível local. A tentativa de analisar as experiências da algaroba e do milho não consistiu rigorosamente em um estudo comparativo, mas em uma possibilidade de aproximarmos situações em que estruturas discursivas produzidas pelo saber técnico e científico não são nem neutras, nem inertes, contrariamente são figurações que qualificam jogos aparentemente muito distintos.

A algaroba no Semiárido do Brasil propiciou a formação de redes diversas, a partir dos produtos derivados pela espécie. Gradativamente a algaroba torna-se um ator ativo na recomposição de espaços, possibilitando a acumulação de recursos e a criação/manutenção de instituições que tanto alteram o jogo de forças - como a criação de assentamentos de reforma agrária - como mantém estruturas conservadoras de poder - a transformação de latifúndios em reservas de conservação, ou ainda, favorece o surgimento de novas alternativas econômicas - como a caprinocultura, 
o comércio madeireiro, de carvão vegetal etc. Através da saga da algaroba, observamos que as dinâmicas endógenas, ainda não completamente explicadas, transformaram o que se pretendia homogêneo em processos, sob múltiplos aspectos heterogêneos, quais sejam, discursos, paisagens e resultados.

O milho híbrido, sob o ponto de vista da ciência, se pretendia radicalmente inovador e revolucionário, entretanto a inovação resultou em homogeneidades e conservadorismos, através do modelo da monocultura intensiva, aumentando a dependência do sistema produtivo em relação aos fertilizantes, empresas sementeiras e instituições de crédito. A relação do discurso científico com os grupos locais foi sempre permeada de confrontos, negociações e riscos, mas os resultados, se não eram previstos, eram previsíveis pelos próprios agricultores: contaminação dos solos e das águas, erosão e degradação. Sem contar com a erosão do próprio tecido social no interior dos grupos camponeses.

De fato, tais experiências de inovação revelaram riscos e excessos, cujas causas repousam na ideia-forca da sociedade como totalidade e no fetiche da modernização que exclui os indivíduos e seus interesses como motor dos processos. Tal conclusão é uma retórica, mas que atualiza uma dimensão da vida social ainda não compreendida pelas políticas de desenvolvimento, que resumidamente foi traduzida por Mendras (1984) na ocasião da realização de uma enquete na região de Bresse (FR), e ouviu o seguinte questionamento de um agricultor: Mais, dites-moi, Monsieur, qu'est-ce que c'est qu'um paysan qui ne produit pas son pain $?^{5}$

\section{REFERÊNCIAS}

ALPHANDERY, Pierre; SENCÉBÉ, Yannick. L'émergence de la sociologie rurale en France (1945-1967). Études Rurales, Paris, n. 183, p. 23-40, sept. 2009.

AZEVEDO, Guilherme. In: I SIMPÓSIO BRASILEIRO SOBRE ALGAROBA, 1982, Natal. Anais... Natal, RN: Empresa de Pesquisa Agropecuária do Rio Grande do Norte, 1982.

BERLAN, Jean-Pierre. D'um changement technique : les mythes du maïs hibryde. 1987. Tese (Doutorado em Ciências Econômicas) - Institut National de la Recherche Agronomique, Paris.

\footnotetext{
${ }^{5}$ Mas diga-me senhor, qual o camponês que não produz o seu pão? (tradução dos autores).
}

BOURDIEU, Pierre. Propos sur le champ politique. Lyon: Press Universitaires, 2000.

BURNETT, Annahid. A "saga da algaroba": ecologia política e escolhas tecnológicas no Semi-Árido Paraíbano. 2007. Dissertação (Mestrado em Sociologia) - Universidade Federal de Campina Grande, Campina Grande, PB.

DÉCHAUX, Jean-Hugues. Norbert Elias et Pierre Bourdieu: analyse concpetuelle comparée. Archives Européenes de Sociologie, Cambridge, v. 34, n. 2, p 364385, nov. 1993.

ELIAS, Norbert. Qu'est-ce que la sociologie? Paris: Presses-Pocker, 1981.

GASPARETTO JUNIOR, Antonio. Plano Marshall. [s.d.]. Disponível em: <http:/ / www.infoescola.com/historia/ plano-marshall/>. Acesso em: 13 jan. 2014.

GERVAIS, Michel; JOLLIVET, Marcel. La fin de la France paysanne. Paris: Éditions du Seuil, 1987.

GOMES, P. A algarobeira. Rio de Janeiro: Ministério da Agricultura, 1961. 49p.

HIDALGO, P. Metodologia de planificacion de cuencas hidrográficas em lãs zonas áridas y semiaridas. In: FAO (Ed.). Planificacion y manejo integrado de cuencas hidrograficas em zonas aridas y semiaridas de America Latina. [S.1.: s.n.], 1996. p. 33-50.

HIRCZAK, Maud; MOLLARD, Amédée. Différenciation par la qualité et le territoire versus coordination sectorialle: conflit ou compromis? L'exemple de la Bresse. Ruralia, Lyon, n. 16-17, p. 1-20, 2005.

LATOUR, Bruno. La science en action. Paris: Découverte, 2000.

LIMA, Paulo César Fernandes. Manejo de áreas individuais de algaroba. Plano de manejo. Petrolina, PE: EMBRAPA Semiárido, 2005. 71p.

MANGELSDORF, Paul. Hybrid corn. Scientific American, New York, v. 185, n. 2, p. 39-47, Aug. 1951.

MELDAU, Débora Carvalho. Actinobacilose. [s.d.]. Disponível em: <http://www.infoescola.com/medicina-veterinaria/actinobacilose/>. Acesso em: 13 jun. 2014.

MENDRAS, Henry. La fin dês paysans, suivi d'une reflexion sur la fin des paysans, vingt ans aprés. Paris: Actes Sud, 1984.

MOREIRA, Roberto José. Agricultura familiar: processos sociais e competitividade. Rio de Janeiro: Mauad, 1999.

NOBRE, F. V. A algarobeira no Nordeste brasileiro, especialmente no Rio Grande do Norte. In: SIMPÓSIO BRASILEIRO SOBRE ALGAROBA, 1., Natal, RN, 1982. Anais... Natal, RN: EMPARN, 1982. p.257-281. (Documentos 7).

SARDAN, Jean-Pierre Olivier. Antrophologie et développement: essai en socio-antrophologie du changement social. Paris: Éditions Karthala, 1995

SILVA, Sebastião. História da Algaroba no Brasil. Teresina, PI: Embrapa Meio Norte, 2000.

TAYLOR, Charles. Introdução à silvicultura tropical. São Paulo: Edgard Blücher, 1969. 